\title{
Mass mixing approach for assessing effects of irrigation on water quality
}

\author{
I. Fraser ${ }^{1}$, S. Douglass ${ }^{1}$, B. Ellwood ${ }^{2} \&$ N. Norton ${ }^{3}$ \\ ${ }^{1}$ URS New Zealand Limited, New Zealand \\ ${ }^{2}$ Meridian Energy Limited, New Zealand \\ ${ }^{3}$ National Institute of Water and Atmospheric Research, New Zealand
}

\begin{abstract}
Predicting the magnitude of any increase in nutrient loads on surface water and groundwater resources under future irrigation scenarios is a complex matter that necessarily relies on modelling approaches to simplify and approximate the key elements of the catchment(s).

Our water quality assessment for the proposed Hunter Downs Irrigation Scheme (HDIS) in New Zealand utilised a mass mixing model to predict nitrate concentrations within groundwater (and surface water) individual catchments. This approach was selected due to the hydrogeology of the scheme area, which is characterised by poorly draining downland hill country intersected by permeable alluvial gravel aquifers which are interconnected with intermittent or perennial streams. This approach requires a robust understanding of the current hydrology, hydrogeology, existing and proposed landuse distribution and associated nutrient concentrations in soil drainage water. Our modelling was calibrated by comparing the output of the existing landuse simulations with the available current day groundwater and surface water quality data, providing further confidence in the modelling output. The approach also allowed the effects of different landuse scenarios and management processes to be considered.

The modelled effects on water quality varied across the scheme area due to differences in existing landuse and interactions between groundwater and surface water that affected the dilution of irrigation drainage. The predicted changes in nutrient concentrations for each catchment were used to assess the risk of increased algae blooms in rivers and coastal lagoon that is of significant ecological and cultural value to the local indigenous Maori people.

In this paper we show how the use of a mass mixing model has provided a realistic basis for quantifying the potential adverse effects of irrigation on groundwater and surface water quality, and evaluating the potential effectiveness of mitigation measures such as nitrification inhibitors.
\end{abstract}

Keywords: nutrients, assessment of environmental effects, surface water, groundwater, modelling, New Zealand. 


\section{Introduction}

The Canterbury region encompasses approximately 42,200 square kilometres of land east of the Southern Alps, between the Waitaki River in the South to the Kaikoura Ranges in the North. The landscape can be generally characterised as extensive alluvial plains extending from the Alps to the coast, with braided alpine rivers cutting across the plains at regular intervals.

The Southern Alps create a rain-shadow effect over the plains, which has historically restricted the intensity of the land use and more recently created demand for water irrigation schemes. Irrigation has enabled Canterbury farmers to accommodate for the climate variability, and to intensify and diversify farming operations. To that end, Canterbury currently accounts for approximately $70 \%$ of the irrigated land in New Zealand.

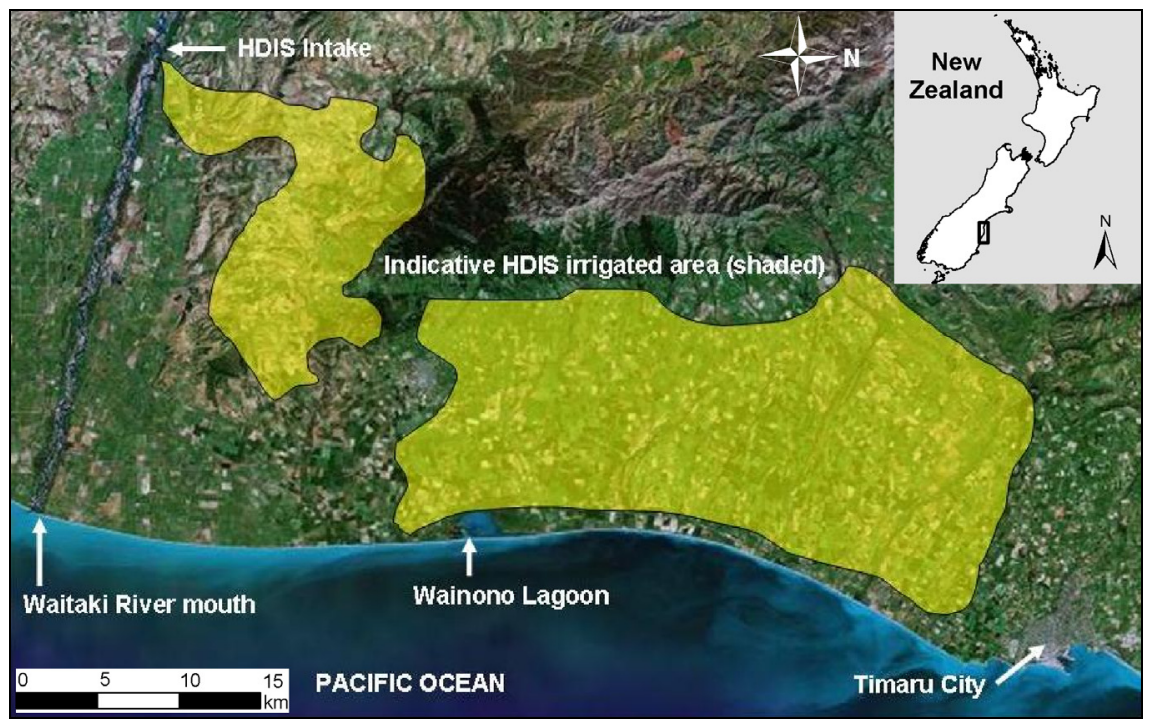

Figure 1: $\quad$ Satellite image showing location of the proposed HDIS (see [14]).

The Hunter Downs Irrigation Scheme (HDIS) is proposed to provide irrigation to approximately 40,000 hectares of South Canterbury that currently has limited groundwater and surface water resources available in-catchment (Fig. 1). Surface water resources in this area are typically ephemeral, with only two catchments in the Scheme area being classified as perennial. Existing utilisation of the surface water and groundwater resources is considered to be very high, with many catchments considered to be over allocated [1].

The HDIS would provide water from an out-of-catchment surface water source (the Waitaki River). Under the New Zealand the Resource Management (RM) Act (1991), the application for such consent must include an assessment of environmental effects (AEE) and consultation with stakeholders and the affected public. This is particularly important due to the presence of a highly valued 
coastal lagoon located at the eastern margin of the HDIS area, as well as the reliance of the community on high quality groundwater for drinking purposes.

\section{Environmental setting}

\subsection{Geology}

The geology of the HDIS Scheme area is dominated by Quaternary deposits of alluvial fans, terraces and floodplains, beach, estuarine and swamp deposits, and extensive loess layers [2]. Terraces of Pleistocene age have been incised by hill catchment rivers to create alluvial valleys of late Quaternary age. The terraced 'Downlands' comprise streams and fan alluvium with loess ridges up to 20 metres thick, and have been created by an accumulation of loess on interfluves [3]. The western boundary of the downlands is formed by the Hunter Hills, a north-south trending fault controlled basement rock range [3].

\subsection{Groundwater / surface water interaction}

The HDIS area incorporates parts of the river catchments from the Pareora River in the north to the Waihao River in the south. Typically, the rivers carry water from the hill country into the alluvial valleys, where surface flow is lost to groundwater. As the rivers approach their lower reaches they typically regain flow from groundwater. For the purposes of the water quality investigations, flow statistics presented by Aitchison-Earl et al. [2] were utilised to determine baseline conditions.

As a result of the low permeability clay and loess immediately below the soil profile, infiltration of drainage water below the root zone is likely to be limited, with $10 \%$ of mean annual rainfall estimated to recharge groundwater on the downlands [4].

The Wainono Lagoon is located in the southern part of the scheme area, a coastal lagoon which has been created by the natural formation of a beach barrier arm that has restricted river flow out to the sea. The lagoon has been influenced significantly by the past actions of humans, who have drained the marginal land around the lagoon and created an outflow arm which takes flow to the Waihao River mouth to the South. The water levels in the lagoon are influenced by storm events, with sea water over-topping the barrier arm frequently.

\section{Contaminants of concern}

A key environmental concern with land use intensification is the generation of water-borne contaminants such as nutrients (various forms of nitrogen and phosphorus), suspended sediment and micro-organisms. Our study focused on the key contaminants nitrate nitrogen (nitrate-N) and phosphorus, although increased sediment and micro-organisms were assessed by others in the project. The environmental consequences of increased nitrogen and phosphorus loads may be divided into two types: i) the potential toxicity effects of nitrate- $\mathrm{N}$ on 
human health and aquatic fauna ii) the nutrient enrichment effects of both nitrogen and phosphorus.

\subsection{Nitrate and toxicity effects}

Nitrate- $\mathrm{N}$ is susceptible to leaching and the potential for this to occur can be increased through a variety of agricultural practices, including ploughing, urine from stock and fertiliser application.

Excessive consumption of nitrate in drinking water has been associated with the risk of methaemoglobinaemia or 'blue baby syndrome' [5]. For this reason, the Drinking Water Standards for New Zealand (2005) has specified the standard for nitrate in potable water at $11.3 \mathrm{~g}$ nitrate- $\mathrm{N} / \mathrm{m}^{3}\left(50 \mathrm{~g} \mathrm{NO}_{3} / \mathrm{m}^{3}\right)[6]$. The World Health Organisation (WHO) recommends the same limit [7]. In order to protect aquatic ecosystems in New Zealand from toxic effects of nitrate- $\mathrm{N}$, the Australian and New Zealand Guidelines for Fresh and Marine Water Quality (ANZECC, 2000 [8]) provide trigger levels that, if exceeded, indicate a potential environmental problem. A trigger value for nitrate toxicity of $7.2 \mathrm{~g} \mathrm{~N} / \mathrm{m}^{3}$ is currently used in New Zealand [9].

\subsection{Nutrient enrichment effects of nitrogen and phosphorus}

Nitrogen and phosphorus are essential plant nutrients and increases in either nutrient can enrich waterways, leading to nuisance algae growth and associated eutrophication effects. Such effects include daily fluctuations in water $\mathrm{pH}$ and dissolved oxygen concentrations, potentially to levels that are lethal for fish and other aquatic fauna. Relationships between nutrient concentrations, hydrological disturbance and algal biomass have been developed for New Zealand rivers [10]. National guidelines set maximum algal cover and biomass thresholds to protect aquatic ecosystems, and also recommend nitrogen and phosphorus concentration limits necessary to achieve those thresholds, depending on other factors such as hydrological disturbance [11]. Nitrate can cause ecological problems as a nutrient at concentrations an order of magnitude lower than the guideline trigger values for toxicity.

\subsection{Water quality status}

Existing surface water sample data showed that water quality varied greatly across the HDIS area. Nitrate concentrations were generally low relative to human and aquatic fauna toxicity guidelines but were high enough to cause breaches in algal cover and biomass guidelines in some rivers during summer [12]. Groundwater quality records were relatively limited but did show a trend of better water quality in wells closer to the streams and rivers, and lower concentrations of nitrates with depth. Overall, nitrate-N concentrations in groundwater were shown to be at low to moderate concentrations relative to toxicity guidelines, reflecting the existing predominantly dryland farming practices. 
Based on the available nutrient data and investigations undertaken by the National Institute of Water and Atmospheric Research (NIWA) during the 2006/2007 summer, the lagoon was classified as varying from eutrophic to hypertrophic under the existing landuse conditions [12].

\section{Assessment methodology}

The hydrogeology of the scheme area is dominated by large areas of downland with limited drainage potential, dissected by valleys containing recent permeable alluvial gravel and interconnected river systems. Due to these characteristics the majority of current rainfall on the downlands currently drains laterally to intermittent streams before discharging to the valley bound alluvial gravels.

Following implementation of the HDIS, excess drainage water is also expected to predominantly drain laterally from the downland areas to the alluvial valleys mixing with groundwater and/or discharging directly to the rivers. Drainage water affected by landuse intensification will therefore be mixed with the existing surface water and groundwater flowing though the alluvial valleys, which is sourced predominantly from dryland areas upgradient of the Scheme area. The resulting groundwater and surface water quality is dependent on a number of variables including the relative size of catchment upgradient of the scheme area, the post irrigation landuse mix and hydrogeology / surface water flow characteristics of the particular catchment.

\subsection{Nitrate nitrogen}

Due to the number of variables influencing groundwater and surface water quality, predicting the magnitude of any increase in nutrient loads necessarily relies on modelling to simplify and approximate the key elements of the catchment(s). The water quality assessment for the HDIS undertaken has utilised a three step process that necessarily involved coupling models between disciplines i.e. 1) an agricultural nutrient budget model 2) a mass mixing hydrogeological model 3) an empirical algae biomass model. The thrust of this paper is on the mass mixing model that has been used to predict nutrient concentrations within groundwater and surface water.

Equation 1 provides the analytical solution which forms the basis of the massmixing model used.

$$
C_{f}=\frac{\left(\left(V_{d} \times C_{d}\right)+\left(V_{i} \times C_{i}\right)\right)}{V_{f}}
$$

Where $C_{f}$ is the final concentration, $V_{d}$ is the volume of drainage water, $C_{d}$ is the concentration of nitrate nitrogen in drainage water, $V_{i}$ is the volume of groundwater influx, $\mathrm{C}_{\mathrm{i}}$ is the concentration of nitrate nitrogen in the groundwater influx, and $\mathrm{V}_{\mathrm{f}}$ is the combined total volume of groundwater flow.

The mass mixing model requires the flux of contaminants from the range of expected landuses to be quantified for each catchment. Drainage concentration were calculated using the OVERSEER ${ }^{\circledR}$ model [13], which estimates the mass of nitrogen lost from the rooting zone under various land use scenarios and mixes it 
with the calculated mean annual rainfall recharge or rainfall and irrigation recharge. The extent of each land use type, combined with the modelled drainage flux of nitrate-N enables the left hand side of the primary equation to be solved. Calculating the groundwater flow volume within the alluvial aquifers required information on the aquifer thickness, width, hydraulic conductivity etc to be obtained for each catchment. In addition, the background concentration of nitrate- $\mathrm{N}$ was established for each catchment. This information enabled the right hand side of the primary equation to be solved.

Figure 2 schematically illustrates the expected pathways for drainage water within the scheme area. The following provides a summary of the principal assumptions used in the modelling.

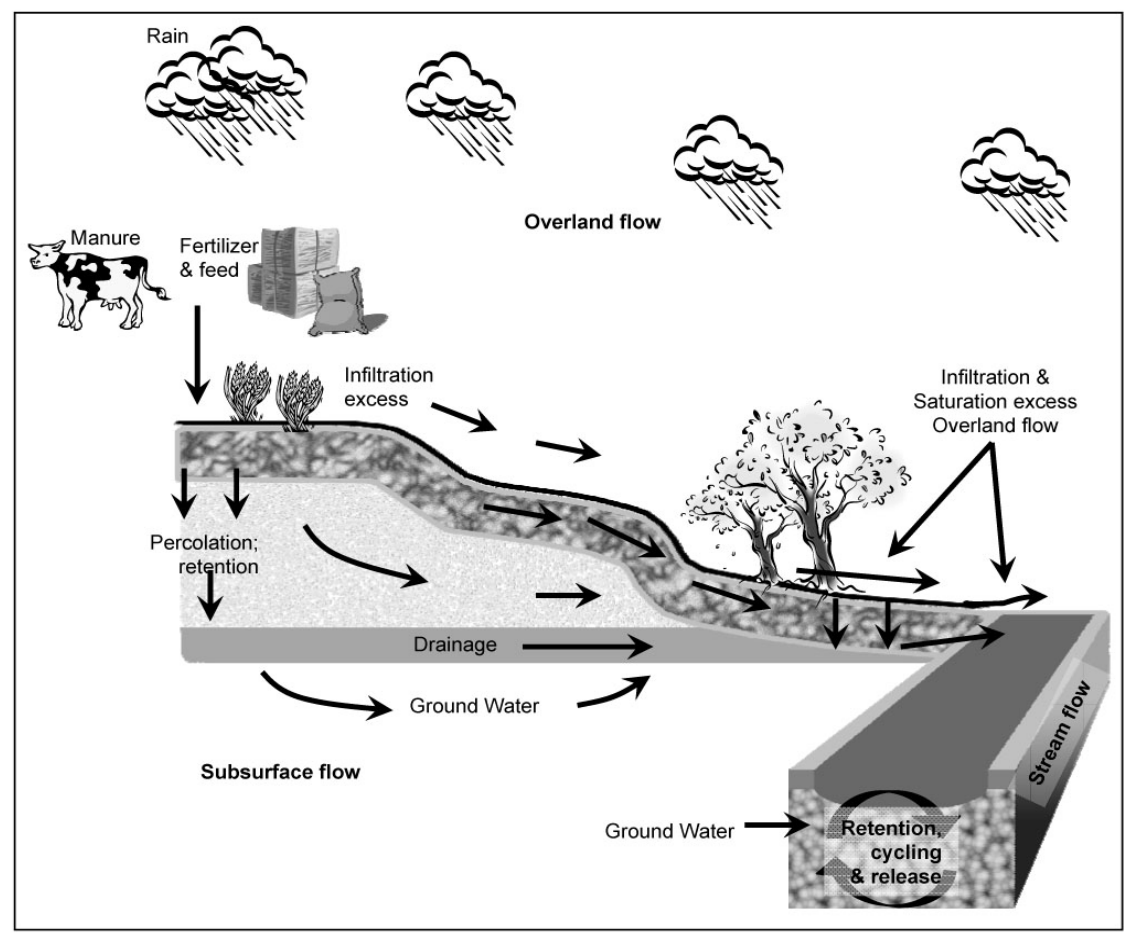

Figure 2: Drainage water pathways.

Drainage Pathways:

- $100 \%$ of drainage from the alluvial flats enters groundwater

- $80 \%$ of drainage from the downlands enters the ephemeral streams and flows to the alluvial flats

- $20 \%$ of drainage/runoff not entering the ephemeral streams either infiltrates through the downlands into the deeper groundwater system and/or is captured in non-irrigated areas 
- $80 \%$ of water entering the ephemeral streams is lost to groundwater on the alluvial flats

The mass-mixing model was calibrated by comparing the modelled output for the existing landuse distribution with the available groundwater quality data at the down gradient end of each catchment. The model assumptions were modified in an iterative manner until the model output showed a reasonable agreement to the existing background environment. However, this calibration of the model also required the model assumptions to be consistent with the conceptual understanding of the behaviour of drainage on the downlands and lowlands.

\subsection{Modelling phosphorus losses}

The mass-mixing model approach was also utilised to assess the potential impacts of increased phosphorus concentration in surface water on the Wainono Lagoon. Current understanding of $\mathrm{P}$ losses to the environment suggests that $\mathrm{P}$ enters surface waterways via overland runoff. Studies in New Zealand show that within a catchment approximately $20 \%$ of the land area will contribute $90 \%$ of the total $\mathrm{P}$ losses. Whilst this is a generalisation, it provides a basis for determining the area of land that may contribute to P loadings within the lagoon catchment. The mass mixing methodology utilised the flux of $\mathrm{P}$ calculated for runoff from the catchment contributing to the Wainono Lagoon and baseline surface water flow statistics to determine $\mathrm{P}$ concentrations in the lagoon under existing and proposed landuses. The mass balance approach estimates a potential increase of $0.03 \mathrm{~g} / \mathrm{m}^{3}$ following irrigation development within the Wainono inflows area, which is more than 1.5 times the modelled average existing Total $\mathrm{P}$ concentration.

\subsection{Best management practices}

The modelling was also used to demonstrate the effectiveness of best management landuse practices (BMPs) in reducing the contaminant loading on groundwater and surface water resources. The mass-mixing model enables the benefits of the BMPs to be quantified for the wider catchment and provides a benchmark against which HDIS can assess the usefulness of promoting BPMs.

The two mitigation measures that have been assessed and the benefits they provide in terms of nitrate nitrogen generation are: nitrification inhibitors (net $30 \%$ reduction in nitrate leaching assumed) and the use of cover crops over the winter period that are reported to reduce nitrate leaching by up to $50 \%,(28 \%$ reduction utilised in modelling).

\section{Results}

Table 1 summarises the results of the mass balance modelling for groundwater and surface water resources within the scheme area. The mass balance modelling indicates that utilising current landuse practices, landuse intensification under the HDIS has the potential to cause increases in nitrate-N in 
groundwater and surface water. Within the Wainono Lagoon peak nitrate-N concentrations are anticipated to increase on the order of $1.8 \mathrm{~g} / \mathrm{m}^{3}$ and $\mathrm{P}$ by around $0.03 \mathrm{~g} / \mathrm{m}^{3}$ above the existing mean concentrations.

Using the mass balance modelling approach indicates that the implementation of the two BMPs evaluated to reduce derived post irrigation nitrate-N groundwater concentrations on average by $18 \%$ and as a result surface water quality improvements are achievable.

Table 1: $\quad$ Mass mixing model output.

\begin{tabular}{|c|c|c|c|c|}
\hline & $\begin{array}{c}\text { Existing } \\
\text { environment } \\
\text { (average) }\end{array}$ & $\begin{array}{c}\text { Modelled } \\
\text { existing }\end{array}$ & $\begin{array}{c}\text { Future } \\
\text { under HD1 }\end{array}$ & Net increase \\
\hline \multicolumn{5}{|c|}{ Nitrite nitrogen $\left(\mathrm{NO}_{\mathrm{x}}-\mathrm{N}\right)-\mathrm{g} / \mathrm{m}^{3}$} \\
\hline Pareora G/W & $5.0-5.5$ & 4.9 & 8.5 & 3.6 \\
\hline Hook River G/W & $2.0-2.5$ & 2.8 & 5.9 & 3.1 \\
\hline Hook River S/W & 0.9 & 1.8 & 5.1 & 3.3 \\
\hline Wainono area G/W & $2.5-3.5$ & 3.4 & 7.3 & 3.9 \\
\hline \multicolumn{5}{|l|}{ Phosphorus (P) $-\mathrm{g} / \mathrm{m}^{3}$} \\
\hline Hook River P & $\begin{array}{l}0.01-0.037 \\
(0.025)\end{array}$ & 0.019 & 0.050 & 0.031 \\
\hline $\begin{array}{l}\text { Wainono lowland streams } \\
\mathrm{P}\end{array}$ & $\begin{array}{l}0.076-0.26 \\
(0.156)\end{array}$ & 0.155 & 0.346 & 0.191 \\
\hline Wainono Lagoon - P & $\begin{array}{l}0.015-1.7 \\
(0.27)\end{array}$ & 0.019 & 0.049 & 0.03 \\
\hline
\end{tabular}

\subsection{Nitrate and toxicity effects}

The results in Table 1 can be directly compared with guidelines to assess the toxicity effects of nitrate-N. With regard to toxicity effects, it is considered that the increases predicted for the HDIS are unlikely to result in widespread breaches of guideline thresholds for nitrate-N toxicity; i.e., the New Zealand Ministry of Health's human drinking Maximum Acceptable Value (MAV) of $11.3 \mathrm{~g}$ nitrate- $\mathrm{N} / \mathrm{m}^{3}$, and the ANZECC trigger value for toxicity to aquatic species of $7.2 \mathrm{~g}$ nitrate- $\mathrm{N} / \mathrm{m}^{3}$. The predicted increase in nitrate-N loads will obviously push the environment closer to these thresholds and therefore increase the risk of breaches. 


\subsection{Nutrient enrichment effects}

It is more difficult to assess thresholds for nutrient enrichment effects in rivers and lakes because factors other than nutrients(e.g. hydrogeological regime, light, temperature and bed substrate) are important for determining the biological response to enrichment. However the results in Table 1 can be used, in conjunction with modelled relationships between these other factors, to predict the increase in algae growth associated with predicted increases in nutrients. While the method is not described here, such an assessment was undertaken [12] and resulted in the prediction that algae biomass could increase by $60 \%$ in rivers and $50 \%$ in the Wainono Lagoon if BMPs were not employed. The quantification of this effect allowed other flow-on effects to be considered, such as the likely extent of aquatic habitat smothered by algae in rivers, the visual impact and risk of toxic blooms in the Wainono Lagoon.

\section{Discussion}

The mass mixing approach utilised is a simplification of the actual conditions, which introduces a number of conservatisms into the assessment of effects. For example nitrate- $\mathrm{N}$ has been conserved throughout the modelling with no allowance being made for natural denitrification processes and/or nutrient uptake which will tend to reduce nitrate-N concentrations in groundwater and surface water. In addition, the dilution effect that is experienced during runoff events when drainage water is flushed from downland areas is not allowed for, with the mass mixing utilising mean annual surface water flow conditions. Furthermore, in all cases the modelling has assumed that the entire catchment within the command area is mixing with the flux of groundwater moving down the alluvial valley(s). In reality this is only the case once nearing the bottom of the catchment, therefore nutrient concentrations are expected to reduce from that calculated with distance upstream.

\section{Conclusion}

The mass mixing modelling approach is a relatively straightforward and appropriately conservative tool for assessing water quality effects associated with the introduction of irrigation into a catchment. However, the approach requires a robust understanding of the current hydrology, hydrogeology, existing and proposed landuse and existing water quality such that the inputs can be appropriately allocated. Due to the outcome of the mass balance approach being highly dependent on the nature of the receiving aquifer, it is most useful when the system can be reasonably well defined in terms of aquifer width, saturated thickness etc. Knowledge of the current landuse distribution and existing water quality status is required in order to calibrate the model and confirm the appropriateness of the principal assumptions used in the modelling process.

The approach is useful because: 
i.) It allowed quantitative predictions of nutrient concentrations in surface waterways can be directly compared to toxicity guidelines.

ii.) The predicted nutrient concentrations can also applied to established biological models to predict biological effects. Such effects include quantitative predictions of increased algae growth and associated negative visual and ecological impacts.

The mass mixing approach has provided a realistic basis for quantifying the potential adverse effects of irrigation on groundwater and surface water quality, and evaluating the potential effectiveness of mitigation measures such as nitrification inhibitors.

\section{References}

[1] Thorley, M. and Ettema, M., 2007. Review of Water Allocation Limits for the South Canterbury Downlands. Unpublished Technical Report U07/09. Environment Canterbury.

[2] Aitchison-Earl, P., Ettema, M., Horrell, G., McKerchar, A., Smith, E., 2006. Pareora-Waihao River: Water Resource Summary. Unpublished Technical Report U06/20. Environment Canterbury. ISBN 1-86937-602-1.

[3] Forsyth, P.J., 2001, Geology of the Waitaki Area: 1:250,000 Geological Map. Institute of Geological and Nuclear Sciences, Lower Hutt, 64pp.

[4] Aitchison - Earl, P., 2005: Deep Aquifer Review: Timaru - Waitaki River. Environment Canterbury unpublished Technical Report U05/02.

[5] Fan, A.M. and Steinberg, V.E., 1996: Health implications if nitrate and nitrite in drinking water: an update on methemoglobinemia occurrence and reproductive and developmental toxicity. Regulatory Toxicology and Pharmacology 23, 35-43.

[6] Ministry of Health, 2005: Drinking Water Standards New Zealand 2005. Ministry of Health, Wellington.

[7] World Heath Organisation, 2004: Guidelines for drinking water quality, 3rd Edition. WHO, Geneva.

[8] ANZECC, 2000: Australian and New Zealand guidelines for fresh and marine water quality. National Water Quality Management Strategy Paper No.4, Australian and New Zealand Environment and Conservation Council \& Agriculture and Resources Management Council of Australia and New Zealand, Canberra, Australia.

[9] Hickey, C., 2002: Nitrate guidelines values in ANZECC 2000. Unpublished memo from Chris Hickey, NIWA, to the Ministry for the Environment dated 30 September 2002.

[10] Biggs, B.J.F., New Zealand periphyton guideline: detecting, monitoring and managing enrichment of streams. Ministry for Environment, Wellington, 2000.

[11] Biggs, B.J.F., Eutrophication of streams and rivers: Dissolved nutrientchlorophyll relationships. Journal of the North American Benthological Society 19(1), pp. 17-31. 
[12] Norton, N., Floeder, S., Drake, D., Hunter Downs Irrigation Scheme: Assessment of potential effects of increased nutrients on aquatic ecology values in rivers and Wainono Lagoon. NIWA Client Report CHC2007-057, Christchurch, 2007.

[13] AgResearch Limited, OVERSEER Nutrient Budgets, www.agresearch. co.nz/overseerweb/default.aspx

[14] Google Maps New Zealand, http://maps.google.co.nz/maps 